\title{
Investigation of the association between matrix metalloproteinase-9 genetic polymorphisms and development of pre-eclampsia in Chinese pregnant women
}

\author{
C. Sun, Q. Zhang, B. Hu and K. Zhang \\ Department of Gynecology and Obstetrics, \\ Second Affiliated Hospital of Zhengzhou University, Zhengzhou, China \\ Corresponding author: K. Zhang \\ E-mail: zhangkke22@163.com
}

Genet. Mol. Res. 15 (3): gmr.15038355

Received December 28, 2015

Accepted April 11, 2016

Published August 12, 2016

DOI http://dx.doi.org/10.4238/gmr.15038355

Copyright (C 2016 The Authors. This is an open-access article distributed under the terms of the Creative Commons Attribution ShareAlike (CC BY-SA) 4.0 License

\begin{abstract}
We carried out a case-control study to evaluate the role of $M M P-9-1562 \mathrm{C} / \mathrm{T}$ (rs3918242) genetic polymorphism in the risk of pre-eclampsia in Chinese pregnant women. Between March 2013 and January 2015, 107 pregnant women with pre-eclampsia were recruited from the Second Affiliated Hospital of Zhengzhou University. Genotyping of $M M P-9$ was carried out using polymerase chain reactionrestriction fragment length polymorphism assay. Unconditional logistic regression analyses revealed that women with the CT genotype (OR $=1.81,95 \% \mathrm{CI}=1.04-3.11)$ exhibited significantly higher risk of preeclampsia than those with the wild-type CC genotype. Moreover, individuals carrying the $\mathrm{T}$ allele were at higher risk of pre-eclampsia than those carrying the $\mathrm{C}$ allele; the adjusted $\mathrm{OR}(95 \% \mathrm{CI})$ was 1.62
\end{abstract}


(1.06-2.47). In conclusion, our study demonstrated that the MMP-9 $-1562 \mathrm{C} / \mathrm{T}$ polymorphism plays an important role in the development of pre-eclampsia in Chinese women. Further studies with large sample sizes are greatly needed to confirm our findings.

Key words: MMP-9; Polymorphism; Pre-eclampsia

\section{INTRODUCTION}

Pre-eclampsia is a serious disease in pregnant women and is associated with high maternal morbidity and mortality in developing countries (Liang et al., 2010). Although the mechanism of pre-eclampsia remains unclear, the development of coronary artery disease results from multiple complex factors, including various environmental factors and their interactions. A previous study reported familial aggregation of pre-eclampsia, which suggests that genetic factors contribute to the pathogenesis of this disease (Morgan and Ward, 1999). Genetic factors account for 25 to $55 \%$ of the risk of developing pre-eclampsia (Thornton and Macdonald, 1999; Salonen Ros et al., 2000).

Matrix metalloproteinases (MMPs) belong to a family of structurally related zincdependent enzymes, which have important roles in restructuring of the extracellular matrix by promoting the secretion of collagenases and gelatinases as well as proteolytic enzymes (Lim et al., 1997; Coolman et al., 2007; Palei et al., 2008). MMP-9 is an important member of the MMPs; it is involved in blastocyst implantation and is an important biochemical mediator of Sertoli cell degeneration. Genetic variations of $M M P-9$ could alter the expression level and structure of the protein (Aas et al., 2003; Bartek and Lukas, 2003). Here, we report a casecontrol study to evaluate the role of the MMP-9 $-1562 \mathrm{C} / \mathrm{T}$ (rs3918242) polymorphism in the risk of pre-eclampsia in Chinese pregnant women.

\section{MATERIAL AND METHODS}

\section{Study subjects}

Between March 2013 and January 2015, 107 pregnant women with pre-eclampsia were recruited from the Second Affiliated Hospital of Zhengzhou University. The diagnostic criteria for pre-eclampsia were as follows: systolic pressure $\square 140 \mathrm{mmHg}$, diastolic pressure $\square 90 \mathrm{mmHg}$, and proteinuria (urinary protein $\square 0.3 \mathrm{~g}$ or urine dipstick protein $\square++$ over a $24-\mathrm{h}$ period) after 20 weeks of gestation. Patients who had a history of intrauterine fetal deaths were excluded from this study.

During the same period, 242 pregnant women with gestational age $\square 20$ weeks were randomly selected from pregnant women visiting the Second Affiliated Hospital of Zhengzhou University for prenatal examination. Control subjects were free of pre-eclampsia, high blood pressure, and abnormal fetal growth.

Demographic data of the pre-eclampsia patients and control subjects were collected from medical records. Written informed consent forms were signed by both patients and control subjects. The study was approved by the Ethics Committee of the Second Affiliated Hospital of Zhengzhou University.

Genetics and Molecular Research 15 (3): gmr.15038355 


\section{DNA extraction and genotyping}

Five fasting venous blood samples were drawn from each study subject, and kept in EDTA-anticoagulant tubes and stored in a freezer at $-20^{\circ} \mathrm{C}$. Genomic DNA was extracted from the peripheral blood using the TIANamp blood DNA kit (Tiangen, Beijing, China). Genotyping of the $M M P-9$ gene was carried out using polymerase chain reaction-restriction fragment length polymorphism (PCR-RFLP) assay. Forward and reverse primer sequences for MMP-9 -1562 C/T were 5'-GCCTGGCACATAGTAGGCCC-3' and 5'-CTTCCTAGCCAGCCGGCATC-3', respectively. PCR products were digested at $37^{\circ} \mathrm{C}$ overnight $(\sim 16 \mathrm{~h})$ with $4 \mathrm{U} S p h \mathrm{I}$. Amplification was checked using $1.5 \%$ agarose gel electrophoresis. In total, $10 \%$ random samples were used to confirm the reproducibility of the genotyping results, and the results showed $100 \%$ consistency.

\section{Statistical analysis}

Statistical differences in the demographic variables and genotype frequencies between the patients and control subjects were determined using the chi-square test for categorical data and the Student $t$-test for continuous variables. Concordance with Hardy-Weinberg equilibrium (HWE) was estimated using the Fisher exact-test. To evaluate the association of pre-eclampsia susceptibility with $M M P-9-1562 \mathrm{C} / \mathrm{T}$ polymorphism, logistic regression analysis was used to calculate adjusted odds ratios (ORs) along with $95 \%$ confidence intervals (CIs) with adjustment for possible confounders. SPSS 17.0 package (SPSS Inc., Chicago, IL, USA) was used to carry out all the statistical analyses, and $\mathrm{P}<0.05$ was considered significant.

\section{RESULTS}

According to chi-square or $t$-test, patients were comparable with control subjects in terms of gestational age $\left(\chi^{2}=1.59, \mathrm{P}=0.06\right)$, tobacco smoking $\left(\chi^{2}=0.87, \mathrm{P}=0.35\right)$, and alcohol use $\left(\chi^{2}=1.47, \mathrm{P}=0.23\right)$ (Table 1$)$. However, we observed significant differences between patients and controls with respect to age $(t=3.18, \mathrm{P}<0.001)$, BMI $(t=4.70, \mathrm{P}<$ $0.001)$, systolic blood pressure $(t=17.78, \mathrm{P}<0.001)$, diastolic blood pressure $(t=20.16, \mathrm{P}<$ $0.001)$, infant birth weight $(t=9.12, \mathrm{P}<0.001)$, and model of delivery $\left(\chi^{2}=18.42, \mathrm{P}<0.001\right)$.

Table 1. Demographic and clinical characteristics of patients with pre-eclampsia and control subjects.

\begin{tabular}{|c|c|c|c|c|c|c|}
\hline Variables & Patients & $\%$ & Controls & $\%$ & $t$ or $\chi^{2}$ test & P value \\
\hline Age, years & \multicolumn{2}{|c|}{$28.85 \pm 5.21$} & \multicolumn{2}{|c|}{$26.85 \pm 5.50$} & 3.18 & $<0.001$ \\
\hline Gestational age, weeks & \multicolumn{2}{|c|}{$27.75 \pm 4.50$} & \multicolumn{2}{|c|}{$26.82 \pm 5.25$} & 1.59 & 0.06 \\
\hline BMI, $\mathrm{kg} / \mathrm{m}^{2}$ & \multicolumn{2}{|c|}{$30.82 \pm 4.21$} & \multicolumn{2}{|c|}{$28.40 \pm 4.53$} & 4.70 & $<0.001$ \\
\hline Systolic blood pressure, $\mathrm{mmHg}$ & \multicolumn{2}{|c|}{$154.60 \pm 20.80$} & \multicolumn{2}{|c|}{$114.55 \pm 18.75$} & 17.78 & $<0.001$ \\
\hline Diastolic blood pressure, $\mathrm{mmHg}$ & \multicolumn{2}{|c|}{$104.64 \pm 18.65$} & \multicolumn{2}{|c|}{$72.57 \pm 10.83$} & 20.16 & $<0.001$ \\
\hline \multicolumn{7}{|l|}{ Tobacco smoking } \\
\hline No & 99 & 92.52 & 230 & 95.04 & & \\
\hline Ever & 8 & 7.48 & 12 & 4.96 & 0.87 & 0.35 \\
\hline \multicolumn{7}{|l|}{ Alcohol consumption } \\
\hline No & 97 & 90.65 & 228 & 94.21 & & \\
\hline Ever & 10 & 9.35 & 14 & 5.79 & 1.47 & 0.23 \\
\hline Infant birth weight, $\mathrm{g}$ & \multicolumn{2}{|c|}{$2759.53 \pm 744.56$} & \multicolumn{2}{|c|}{$3358.52 \pm 465.61$} & 9.12 & $<0.001$ \\
\hline \multicolumn{7}{|l|}{ Model of delivery } \\
\hline Normal & 44 & 41.12 & 159 & 65.70 & & \\
\hline Caesarean & 63 & 58.88 & 83 & 34.30 & 18.42 & $<0.001$ \\
\hline
\end{tabular}

$\mathrm{BMI}=$ body mass index.

Genetics and Molecular Research 15 (3): gmr.15038355 
Of the patients, 67 (62.62\%), 33 (30.84\%), and $7(6.54 \%)$ had the CC, CT, and TT genotype, respectively. Of the control subjects, 178 (73.55\%), 53 (21.90\%), and $11(4.55 \%)$ displayed the CC, CT, and TT genotype, respectively (Table 2). The genotype distributions of $M M P-9-1562 \mathrm{C} / \mathrm{T}$ are shown in Table 2 . The chi-square test indicted no statistical difference in the genotype frequencies of $M M P-9-1562 \mathrm{C} / \mathrm{T}$ between the two study groups $\left(\chi^{2}=4.24, \mathrm{P}\right.$ $=0.12$ ). The genotype distributions of $M M P-9-1562 \mathrm{C} / \mathrm{T}$ in patients were in concordance with the HWE $(\mathrm{P}=0.30)$, whereas those in controls were not $(\mathrm{P}=0.01)$.

Table 2. Genotype distribution of MMP-9 -1562 C/T in patients with pre-eclampsia and control subjects.

\begin{tabular}{l|c|c|c|c|c|c|c|c}
\hline$M M P-9-1562 \mathrm{C} / \mathrm{T}$ & Patients & $\%$ & Controls & $\%$ & $\chi^{2}$ test & P value & \multicolumn{2}{|c}{ P for HWE } \\
\hline CC & & & & & & & In patients & In controls \\
\hline CT & 67 & 62.62 & 178 & 73.55 & & & & \\
\hline TT & 33 & 30.84 & 53 & 21.90 & & & & 0.01 \\
\hline
\end{tabular}

HWE $=$ Hardy-Weinberg equilibrium.

Unconditional logistic regression analyses revealed that individuals with the CT genotype had significantly higher risk of pre-eclampsia than those with the CC genotype (OR $=1.81,95 \% \mathrm{CI}=1.04-3.11)($ Table 3$)$. Moreover, individuals carrying the $\mathrm{T}$ allele were at increased risk of pre-eclampsia as compared to those having the $\mathrm{C}$ allele; the adjusted OR $(95 \% \mathrm{CI})$ was $1.62(1.06-2.47)$.

Table 3. Association between MMP-9 -1562 C/T genetic polymorphism and development of pre-eclampsia.

\begin{tabular}{l|c|c|c|c|c|c}
\hline$M M P-9-1562 \mathrm{C} / \mathrm{T}$ & Patients & $\%$ & Controls & $\%$ & OR (95\%CI) & P value \\
\hline CC & 65 & 60.75 & 178 & 73.55 & 1.0 (Ref.) & - \\
\hline CT & 35 & 32.71 & 53 & 21.9 & $1.81(1.04-3.11)$ & 0.02 \\
\hline TT & 7 & 6.54 & 11 & 4.55 & $1.74(0.55-5.16)$ & 0.27 \\
\hline Allele & & & & & & \\
\hline C & 165 & 154.21 & 409 & 169 & 1.0 (Ref.) & - \\
\hline T & 49 & 45.79 & 75 & 31 & $1.62(1.06-2.47)$ & 0.02 \\
\hline
\end{tabular}

Ref. $=$ Reference

\section{DISCUSSION}

Previous epidemiological studies have indicated that various polymorphisms in genes such as interleukin-27, transforming growth factor beta-1, estrogen receptor alpha, cystathionine gamma-lyase, and cyclooxygenase 2 might play a critical role in the development of preeclampsia (Deepthi et al., 2015; El-Beshbishy et al., 2015; Khani et al., 2015; Mrozikiewicz et al., 2015; Ren et al., 2015; Chen et al., 2016). Here, we carried out a case-control study to estimate the role of the $M M P-9-1562 \mathrm{C} / \mathrm{T}$ polymorphism in the risk of pre-eclampsia, and we observed that the $\mathrm{CT}$ genotype and $\mathrm{T}$ allele of $M M P-9-1562 \mathrm{C} / \mathrm{T}$ were associated with elevated risk of pre-eclampsia in Chinese pregnant women.

Multiple experimental studies have investigated the association between MMP-9 expression and pre-eclampsia development; however, the results are inconsistent (Mckirdy and Marks, 2012; Wang et al., 2013; Yang et al., 2013; Lockwood et al., 2014; Rasstrigina et 
al., 2014). Wang et al. (2013) reported that decreased expression levels of MMP-9 regulate trophoblast invasion and migration, and thus influence the pathogenesis of pre-eclampsia. Yang et al. (2013) indicated that MMP-9 expression might have an important role in the pathogenesis of pre-eclampsia through regulation of trophoblast invasion. Lockwood et al. (2014) suggested that augmented expression of MMP-9 in decidual cells could influence the development of pre-eclampsia. However, Mckirdy and Marks (2012) indicated that high MMP-9 expression was observed in early gestation, but no difference was found in protein levels of MMP-9 between pre-eclampsia and normal pregnant women.

Additionally, several studies have reported an association between MMP-9 genetic polymorphism and the development of pre-eclampsia; however, the results of these studies are inconclusive (Coolman et al., 2007; Fraser et al., 2008; Palei et al., 2010, 2012; Luizon et al., 2012; Rahimi et al., 2013, 2014, 2015). Some studies suggested that the CC genotype or $\mathrm{C}$ allele of $M M P-9-1562 \mathrm{C} / \mathrm{T}$ is associated with increased risk of developing pre-eclampsia in Caucasian pregnant women (Coolman et al., 2007; Luizon et al., 2012; Rahimi et al., 2013, 2014, 2015). However, Fraser et al. (2008) suggested that MMP-9 $-1562 \mathrm{C} / \mathrm{T}$ genetic polymorphism failed to present any significant association with pre-eclampsia. Two studies in Brazil reported that $M M P-9$ genetic variation is correlated with gestational hypertension, but not with pre-eclampsia (Palei et al., 2010, 2012). In our study, we found that MMP-9 -1562 $\mathrm{C} / \mathrm{T}$ genetic polymorphism contributes to the development of pre-eclampsia.

In conclusion, our study demonstrated that the $M M P-9$ genetic polymorphism may play an important role in the development of pre-eclampsia in Chinese pregnant women. Further studies with large sample sizes are greatly needed to confirm our findings.

\section{Conflicts of interest}

The authors declare no conflict of interest.

\section{ACKNOWLEDGMENTS}

We thank the staff at the Second Affiliated Hospital of Zhengzhou University for their help in this study.

\section{REFERENCES}

Aas PA, Otterlei M, Falnes PO, Vågbø CB, et al. (2003). Human and bacterial oxidative demethylases repair alkylation damage in both RNA and DNA. Nature 421: 859-863. http://dx.doi.org/10.1038/nature01363

Bartek J and Lukas J (2003). DNA repair: Damage alert. Nature 421: 486-488. http://dx.doi.org/10.1038/421486a

Chen P, Gong Y, Pu Y, Wang Y, et al. (2016). Association between polymorphisms in IL-27 gene and pre-eclampsia. Placenta 37: 61-64. http://dx.doi.org/10.1016/j.placenta.2015.11.003

Coolman M, de Maat M, Van Heerde WL, Felida L, et al. (2007). Matrix metalloproteinase-9 gene -1562C/T polymorphism mitigates preeclampsia. Placenta 28: 709-713. http://dx.doi.org/10.1016/j.placenta.2006.06.017

Deepthi G, Chaithri PK, Latha P, Rani VU, et al. (2015). TGFB1 functional gene polymorphisms (C-509T and T869C) in the maternal susceptibility to pre-eclampsia in South Indian women. Scand. J. Immunol. 82: 390-397. http://dx.doi. org $/ 10.1111 / \mathrm{sji} .12342$

El-Beshbishy HA, Tawfeek MA, Al-Azhary NM, Mariah RA, et al. (2015). Estrogen receptor alpha (ESR1) gene polymorphisms in pre-eclamptic Saudi patients. Pak. J. Med. Sci. 31: 880-885.

Fraser R, Walker JJ, Ekbote UV, Martin KL, et al. (2008). Interleukin-4 -590 (C>T), toll-like receptor-2 +2258 (G>A) and matrix metalloproteinase-9 -1562 (C>T) polymorphisms in pre-eclampsia. BJOG 115: 1052-1056, discussion 1056.

Genetics and Molecular Research 15 (3): gmr.15038355 
http://dx.doi.org/10.1111/j.1471-0528.2008.01771.x

Khani M, Amani D, Taheripanah R, Sanadgol N, et al. (2015). Transforming growth factor beta-1 (TGF-b1) gene single nucleotide polymorphisms (SNPs) and susceptibility to pre-eclampsia in Iranian women: A case-control study. Pregnancy Hypertens. 5: 267-272.

Liang J, Zhu J, Dai L, Li X, et al. (2010). Maternal mortality in China, 1996-2005. Int. J. Gynaecol. Obstet. 110: 93-96. http://dx.doi.org/10.1016/j.ijgo.2010.03.013

Lim KH, Zhou Y, Janatpour M, McMaster M, et al. (1997). Human cytotrophoblast differentiation/invasion is abnormal in pre-eclampsia. Am. J. Pathol. 151: 1809-1818.

Lockwood CJ, Basar M, Kayisli UA, Guzeloglu-Kayisli O, et al. (2014). Interferon-g protects first-trimester decidual cells against aberrant matrix metalloproteinases 1, 3, and 9 expression in preeclampsia. Am. J. Pathol. 184: 2549-2559. http://dx.doi.org/10.1016/j.ajpath.2014.05.025

Luizon MR, Palei AC and Sandrim VC (2012). Polymorphisms and haplotypes in candidate genes related to angiogenesis and endothelial dysfunction in preeclampsia. J. Pregnancy 2012: 914704. http://dx.doi.org/10.1155/2012/914704

Mckirdy A and Marks L (2012). PP060. Matrix metalloproteinases-2 and -9 and their inhibitors: A role in the development of pre-eclampsia? Pregnancy Hypertens. 2: 274-275. http://dx.doi.org/10.1016/j.preghy.2012.04.171

Morgan T and Ward K (1999). New insights into the genetics of preeclampsia. Semin. Perinatol. 23: 14-23. http://dx.doi. org/10.1016/S0146-0005(99)80056-1

Mrozikiewicz PM, Bogacz A, Omielańczyk M, Wolski H, et al. (2015). The importance of rs1021737 and rs482843 polymorphisms of cystathionine gamma-lyase in the etiology of preeclampsia in the Caucasian population. Ginekol. Pol. 86: 119-125. http://dx.doi.org/10.17772/gp/1998

Palei AC, Sandrim VC, Cavalli RC and Tanus-Santos JE (2008). Comparative assessment of matrix metalloproteinase (MMP)-2 and MMP-9, and their inhibitors, tissue inhibitors of metalloproteinase (TIMP)-1 and TIMP-2 in preeclampsia and gestational hypertension. Clin. Biochem. 41: 875-880. http://dx.doi.org/10.1016/j.clinbiochem.2008.04.015

Palei AC, Sandrim VC, Duarte G, Cavalli RC, et al. (2010). Matrix metalloproteinase (MMP)-9 genotypes and haplotypes in preeclampsia and gestational hypertension. Clin. Chim. Acta 411: 874877.

Palei AC, Sandrim VC, Amaral LM, Machado JS, et al. (2012). Matrix metalloproteinase-9 polymorphisms affect plasma MMP-9 levels and antihypertensive therapy responsiveness in hypertensive disorders of pregnancy. Pharmacogenomics J. 12: 489-498. http://dx.doi.org/10.1038/tpj.2011.31

Rahimi Z, Rahimi Z, Shahsavandi MO, Bidoki K, et al. (2013). MMP-9 (-1562 C:T) polymorphism as a biomarker of susceptibility to severe pre-eclampsia. Biomarkers Med. 7: 93-98. http://dx.doi.org/10.2217/bmm.12.95

Rahimi Z, Rahimi Z, Aghaei A and Vaisi-Raygani A (2014). AT2R -1332 G:A polymorphism and its interaction with AT1R 1166 A:C, ACE I/D and MMP-9 -1562 C:T polymorphisms: risk factors for susceptibility to preeclampsia. Gene 538: 176-181. http://dx.doi.org/10.1016/j.gene.2013.12.013

Rahimi Z, Kazemian L, Malek-Khosravi S, Najafi F, et al. (2015). Matrix metalloproteinase-7 A-181G and its interaction with matrix metalloproteinase-9 C-1562T polymorphism in preeclamptic patients: association with malondialdehyde level and severe preeclampsia. Arch. Gynecol. Obstet. 291: 45-51. http://dx.doi.org/10.1007/s00404-014-3376-4

Rasstrigina IM, Milovanov AP, Fokina TV and Kadyrov M (2014). [The intensity of expression of matrix metalloproteinases type 2 and type 9 by invasive trophoblast cells in uncomplicated pregnancy and preeclampsia]. Arkh. Patol. 76: 24-29.

Ren R, Gao M, Fan P, Liu X, et al. (2015). [Association study between -765G $>$ C and -1195G $>$ A functional polymorphisms in the cyclooxygenase 2 gene and risk of preeclampsia]. Zhonghua Yi Xue Yi Chuan Xue Za Zhi 32: 245-249.

Salonen Ros H, Lichtenstein P, Lipworth L and Cnattingius S (2000). Genetic effects on the liability of developing preeclampsia and gestational hypertension. Am. J. Med. Genet. 91: 256-260. http://dx.doi.org/10.1002/(SICI)1096$\underline{\text { 8628(20000410)91:4<256::AID-AJMG3>3.0.CO;2-T }}$

Thornton JG and Macdonald AM (1999). Twin mothers, pregnancy hypertension and pre-eclampsia. Br. J. Obstet. Gynaecol. 106: 570-575. http://dx.doi.org/10.1111/j.1471-0528.1999.tb08326.x

Wang L, Zhang D, Yu Y, Guan H, et al. (2013). RNA interference-mediated silencing of laminin receptor 1 (LR1) suppresses migration and invasion and down-regulates matrix metalloproteinase (MMP)-2 and MMP-9 in trophoblast cells: implication in the pathogenesis of preeclampsia. J. Mol. Histol. 44: 661-668. http://dx.doi.org/10.1007/s10735$\underline{013-9515-6}$

Yang ZM, Luo X, Bai B and Qi HB (2013). Expression of KLF-8 and MMP-9 in placentas and their relationship with the pathogenesis of preeclampsia. Zhonghua Fu Chan Ke Za Zhi 48: 755-758.

Genetics and Molecular Research 15 (3): gmr.15038355 